\title{
Lumbosacral plexopathy due to dermoid cyst of the greater omentum
}

\author{
C. Leno, O. Combarros and J. Berciano.
}

Department of Medicine (Section of Neurology), National Hospital Marqués of Valdecilla, Faculty of Medicine, 39008 Santander, Spain.

\begin{abstract}
Summary: We describe the case of a 66 year old woman with a lumbosacral plexopathy secondary to the compression produced by a dermoid cyst of the omentum, a complication not previously reported.
\end{abstract}

\section{Introduction}

The trajectory of the lumbosacral plexus makes it liable to compression on direct invasion by many tumours, although such involvement is not a frequent

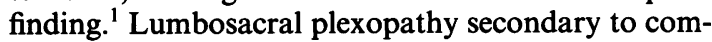
pression by a dermoid cyst of the greater omentum has not been described previously.

\section{Case report}

A 66 year old woman was admitted in July 1979 for distal weakness of the right leg of 3 months duration. For the last 6 months, the patient had also suffered pain and paraesthesiae of the lateral aspect of the right leg. At 54 years old, she had transitory right sciatica and an operation of unknown type had been carried out in the lumbar region. On examination, muscle power of the right leg was reduced in flexors and extensors of the foot, flexors of the knee and gluteus medius. There was atrophy of the right vastus medialis, and atrophy with erythrocyanosis and coldness of the right leg. The sweat test with subcutaneous pilocarpine ${ }^{2}$ showed reduction of sweating on the anterolateral aspect and the dorsum of the right foot. The right Achilles tendon reflex was absent and there was hypoaesthesia to touch and temperature in the anterolateral aspect of the right leg. On rectal examination the pouch of Douglas was found to be occupied by a tumour.

Routine laboratory tests including cerebrospinal fluid were normal. An electromyogram revealed a reduced recruitment pattern upon maximum activity with some fibrillations at rest in the right quadriceps femoris, tibialis anterior and gastrocnemius, but no

Correspondence: J. Berciano, M.D.

Accepted: 5 September 1986 abnormality in the right biceps femoris. Sensory and motor conduction studies of both tibial nerves were normal. Radiological studies of the lumbar spine showed advanced multilevel disk degeneration with marked osteophyte formation; however, there were no abnormalities on myelography with metrizamide. A mass in the lesser pelvis with calcification which looked like a tooth was seen on a plain film of the abdomen (Figure 1), on barium enema and on an intravenous pyelogram; abdominal echography gave similar findings.

At operation a cyst of the greater omentum measuring $8 \times 6 \times 6 \mathrm{~cm}$ was found, embedded in the lesser pelvis. The left ovary was atrophied and the retroperitoneal space was normal. Macroscopically it was a cystic tumour which contained sebaceous material, with a solid area in which there was a welldeveloped tooth. On histological examination, the wall of the tumour consisted of dense collagenous tissue lined with flat stratified epithelium, in the centre of which ovarian stroma was identified. The pain and paresthesiae disappeared after the operation; 6 years later, the above-mentioned deficits remained unchanged.

\section{Discussion}

The signs and symptoms found in our patient suggest either a right $L_{4}-S_{1}$ radiculopathy or lumbosacral plexopathy. There were severe dysautonomic segmentary vascular and cutaneous phenomena which indicated that the lesion was sited at post-foraminal level in the plexus. ${ }^{2}$ As was to be expected, the dermoid cyst of the omentum was sited in the pre-sacral region of the lesser pelvis and compressing the right lumbosacral plexus. Dermoid cyst of the omentum can be symptomless ${ }^{3,4}$ or present with abdominal pain ${ }^{5,6}$ or

(C) The Fellowship of Postgraduate Medicine, 1987 


\section{References}

1. Stevens, J.C. Lumbosacral plexus lesions. In: Dyck, P.J., Thomas, P.K., Lambert, E.H. \& Bunge, R. (ed) Peripheral Neuropathy. W.B. Saunders, Philadelphia, 1984, pp 1425-1434.

2. Mumenthaler, M.\& Schliack, H. Patologia de los nervios periféricos: diagnóstico y tratamiento. Toray, Barcelona, 1976, pp 79-87, 324-335.

3. D'Abreu, A.L. A dermoid cyst of the great omentum with unusual attachments. Br J Surg 1934, 22: 390-391.

4. Warfield, J.O. Omental dermoid cyst. Am Surg 1956, 22: 652-656.

5. Lazarus, J.A. \& Rosenthal, A.A. Synchronous dermoid cyst of the great omentum and of the ovary. Ann Surg 1931, 93: 1269-1273.

6. Prado, W.D. Double tératome abdominal. Sem Hop Paris 1975, 51: 2747-2749.

7. Judd, E.S. \& Fulcher, O.H. Dermoid cyst of the abdomen. Surg Clin North Am 1933, 13: 835-842.

8. Love, R.J.M. Dermoid cyst simulating gastric ulcer. $\mathrm{Br} J$ Surg 1930, 18: 339-340.

9. Mumey, N. Dermoid cyst of the great omentum. Am J Surg 1928, 5: 56-60.

10. Hogan, M.L., Barber, D.D. \& Kaufman, R.H. Dermoid cyst in supernumerary ovary of the greater omentum: report of a case. Obstet Gynecol 1967, 29: 405-408.

11. Printz, J.L., Choate, J.W., Townes, P.L. \& Harper, R.C. The embryology of supernumerary ovaries. Obstet Gynecol 1973, 41: 246- 252.

12. Bell, D.A. \& Demopoulos, R.I. Benign cystic teratoma in the omentum: a mechanism of its development. Diagn Gynecol Obstet 1980, 2: 205-208.

13. Ekbladh, L.E. \& Fihburne, J.I. Parasitized dermoid cyst of the omentum. Obstet Gynecol 1973, 42: 458-460.

14. Kearney, M.S. Synchronous benign teratomas of the greater omentum and ovary: case report. Br J Obstet Gynaecol 1983, 90: 676-679.

15. Willis, R.A. Pathology of Tumours. Butterworths, London, 1967, pp 959-1003.

simulating a gastric ulcer. ${ }^{7,8}$ The location of a dermoid reported in one case, ${ }^{9}$ which clinically took the form of wer right quadrant of the abdomen and been determined. It has been thought that they may or that, starting as ovarian tumours, they become tum. ${ }^{12-14}$ In our patient the atrophied ovary and the presence of ovarian stroma in the teratoma, ${ }^{14}$ an exceptional finding in these tumours, ${ }^{15}$ support the

We thank Mrs Carol Elsden for the English translation and Miss Marta de la Fuente for secretarial assistance. 